\title{
Event-related potentials (ERPs) in ecstasy (MDMA) users during a visual oddball task
}

\author{
S. Mejias ${ }^{\mathrm{a}}$, M. Rossignol ${ }^{\mathrm{b}}$, D. Debatisse ${ }^{\mathrm{c}}$, E. Streel $^{\mathrm{d}}$, \\ L. Servais ${ }^{\mathrm{a}}$, J.M. Guérit ${ }^{\mathrm{e}}$, P. Philippot ${ }^{\mathrm{b}}$, \\ S. Campanella ${ }^{\mathrm{b}, *}$

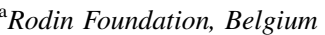 \\ ${ }^{\mathrm{b}}$ Catholic University of Louvain-la-Neuve, Cognitive Neurosciences and ECSA Unit, \\ Faculté de Psychologie, Unité NESC, Place du Cardinal Mercier 10, \\ B-1348 Louvain-la-Neuve, Belgium \\ ${ }^{\mathrm{c}}$ Neuromonitoring and Neurophysiological Unit, CHUV Lausanne, Switzerland \\ ${ }^{\mathrm{d}}$ University of Brussels, ISEPK and CHU Brugmann, Service de Psychiatrie, Brussels, Belgium \\ ${ }^{\mathrm{e}}$ University of Louvain, Faculty of Medecine, NCHM Unit, Brussels, Belgium
}

Received 28 June 2004; accepted 11 November 2004

\begin{abstract}
Ecstasy is the common name for a drug mainly containing a substance identified as 3,4methylenedioxymethamphetamine (MDMA). It has become popular with participants in "raves", because it enhances energy, endurance and sexual arousal, together with the widespread belief that MDMA is a safe drug [Byard, R.W., Gilbert, J., James, R., Lokan, R.J., 1998. Amphetamine derivative fatalities in South Australia. Is "ecstasy" the culprit? Am. J. Forensic Med. Pathol. 19, 261-265]. However, it is suggested that this drug causes a neurotoxicity to the serotonergic system that could lead to permanent physical and cognitive problems.

In order to investigate this issue, and during an ERP recording with 32 channels, we used a visual oddball design, in which subjects (14 MDMA abusers and 14 paired normal controls) saw frequent stimuli (neutral faces) while they had to detect as quickly as possible rare stimuli with happy or fearful expression.

At a behavioral level, MDMA users imply longer latencies than normal controls to detect rare stimuli. At the neurophysiological level, ERP data suggest as main result that the N200 component, which is involved in attention orienting associated to the detection of stimulus novelty (e.g. [Campanella, S., Gaspard, C., Debatisse, D., Bruyer, R., Crommelinck, M., Guérit, J.M., 2002. Discrimination of emotional facial expression in a visual oddball task: an ERP study. Biol. Psychol. 59, 171-186]), shows shorter latencies for fearful rare stimuli (as compared to happy ones), but only
\end{abstract}

\footnotetext{
* Corresponding author. Tel.: +32 10473808 ; fax: +32 10473774 .

E-mail address: salvatore.campanella@psp.ucl.ac.be (S. Campanella).
} 
for normal controls. This absence of delay was interpreted as an attentional deficit due to MDMA consumption.

(C) 2005 Elsevier B.V. All rights reserved.

Keywords: Event-related potentials; MDMA users; Oddball; N2/P3a; P3b

\section{Introduction}

Ecstasy (3,4-methylenedioxymethamphetamine) or MDMA is a popular recreational drug among young outgoing people because of its proprieties of mood enhancers, especially in discotheques. This drug benefits of the widespread idea that its use is quite safe (Dowling et al., 1987; Byard et al., 1998). However, during those last few years, many researchers have tried to demonstrate the importance of the damages generated by MDMA, such as hyperthermia and disseminated intravascular coagulation, fatal arrhythmia, organs destruction, or even death (Fineschi et al., 1999). Mental disorder such as depression (Benazzi and Mazzoli, 1991; McCann and Ricaurte, 1991; McCardle et al., 2004) or panic disorder (McCann and Ricaurte, 1992) have also been related to MDMA consumption.

A great part of MDMA studies have been conducted on animals (rodents, dogs, large variety of primates) and many of those studies concern MDMA toxic and long-lasting effects on brain neurons. MDMA is an indirect serotonergic agonist and also influences other systems of neurotransmission. MDMA frees serotonin and inhibits its reuptake: this increases the amount of serotonin in the synaptic slit, the main consequence being a longlasting reduction of serotonin and serotonergic activities (Audenaert, 2003). Accordingly, other findings showed that MDMA causes toxic effects on brain serotonin (5-HT) neurons and dose-related reduction of brain 5-HT concentrations and transporters, as well as histological evidence of 5-HT axon degeneration (Steele et al., 1994 for a review). Studies also underline that most severe reduction of 5-HT activities occurred in the rats neocortex, striatum, and hippocampus (see Lyles and Cadet, 2003 for a review). Neuronal recovery seems to occur over several months in rats but seems to be only partial in monkeys and primates (Ricaurte et al., 2000).

If serotoninergic activities seem to be affected by MDMA consumption, dopaminereleasing effects of MDMA have also been demonstrated (Steele et al., 1994; Brodkin et al., 1993). Overall, it has been suggested that all these neurochemical effects of MDMA consumption could lead to severe cognitive deficits. Nevertheless, the applicability of those findings on humans have been contested for several reasons: (1) the doses used in animal studies are much higher than the ones taken by humans; and (2) the drug administrations differ between animals and humans and there are potential species differences (see Ricaurte et al., 2000 for a discussion). As a consequence, a deeper review of the literature suggests that the impact of MDMA consumption on human cognition is not yet clearly circumscribed, as revealed, for instance, by the following heterogeneous results.

On the one hand, some authors used neuropsychological tests such as the test for attentional performance (TAP) or the Wechsler adult intelligence scale-revised (WAIS-R) (for e.g. see in Gouzoulis-Mayfrank et al., 2000), and psychopathological scales, such as the Beck Depression Inventory and the Spielberg State-Trait Anxiety Inventory (see, e.g. 
Verkes et al., 2001). Results suggest cognitive impairments and psychiatric complaints as depression or anxiety when the use of MDMA is repeated (Gouzoulis-Mayfrank et al., 2000). Those cognitive impairments are quite large and are underlined for different kinds of memory, central executive functions, reasoning and semantic recognition. It was moreover suggested that these deficits could be referred to the serotonin deficit (for reviews, see Montoya et al., 2002; Parrott, 2002; Lyles and Cadet, 2003). Indeed, several studies have shown that 5-HT depletion could induce memory deficits (for review, see Altman and Normile, 1998) as well as depressive and anxiety disorders (Deakin, 1998). However, contrasting data evidenced only moderate cognitive impairments in MDMA users by using the same material: Thomasius et al. (2003) did not show any significant differences between groups when the TAP test was used, and identical results were observed with the WAIS-R: Krystal et al. (1992) did not underline any difference between groups for the performance on this test.

On the other hand, functional neuroimaging studies applying positron emission tomography (PET) on humans revealed central nervous alterations after the repeated use of ecstasy: McCann et al. (1998) found a reduction of serotonin transporter in MDMA users compared to controls. Indeed, these authors found reduced glucose metabolic rates in MDMA group compared to controls in hippocampus and striatum (Obrocki et al., 1999), striatum, amygdale and cingulate (Buchert et al., 2001) and increased glucose rates in Brodmann's area 10 and 11 (Obrocki et al., 1999). Those results seem to show that MDMA is neurotoxic for the serotonergic system and could then explain the damage to the central nervous function as well as the neuropsychiatric deficits (Obrocki et al., 2002). However, for instance, Gamma et al. (2001) measured with PET the cerebral blood flow during a memory cognitive task: the results did not differ between the group of ecstasy users and the control group. It is also unclear whether ecstasy abuse causes delayed or chronic alterations of the human nervous system (McCann and Ricaurte, 1993). Semple et al. (1999) have reported evidence for recovery from alteration of brain 5-HT neurons after withdrawing MDMA, and Reneman et al. (2001) observed no difference in the 5-HT transporter density in individuals who stopped using MDMA more than 2 years ago when compared to controls. Another study did not show significant global or regional cerebral blood flow difference in abstinent MDMA users (Chang et al., 2000).

It is also interesting to note that a decrease in dopamine transporter in MDMA users, with consequent poor motor/memory performances, have been reported (Volkow et al., 2001), whereas in an isolated case, Koch and Galloway (1997) showed that the striatal levels of dopamine in the brain of a chronic ecstasy user were within the normal range.

On the whole, it appears that current neuroimaging studies on humans have not been able, at least up to now, to clearly define whether MDMA consumption led automatically to cognitive impairments. Due to the ever-increasing problem of drug abuse among young people and adolescents (Neiman et al., 2000), it seems to us particularly relevant to clarify whether MDMA users will show cognitive deficits. In the present study, we choose to confront MDMA users and controls non-abusers to a variation of the visual oddball paradigm, in which subjects were confronted with one frequent stimulus (a neutral face) and two deviant ones they have to detect as quickly as possible (a happy and a fearful face). This choice was guided by several reasons. 
Many ERP studies have used an "oddball" paradigm, in which subjects are asked to detect, amongst a series of standard stimuli, an infrequent deviant one. The detection of stimulus change may play a role in directing attention to events of biological importance (Halgren and Marinkovic, 1995). This is indexed by two main ERP components: (1) When subjects are placed in attentive conditions, deviant visual stimuli evoke a N2 component peaking at occipital electrodes around $250 \mathrm{~ms}$, which indicates a switch of attention to biologically significant events in order to cope with them (Campanella et al., 2002; Halgren and Marinkovic, 1995); (2) a P3b component maximally recorded at parietal sites around $450 \mathrm{~ms}$, which is functionally related to later conscious, decisional and premotor responserelated stages (Bentin et al., 1999). In other words, this kind of detection task will allows us to separate the attentional (preparation-to-process) and the response-related (preparationto-respond) steps implied during the task. Our principal aim will be to examine whether there is any difference, in the MDMA users group compared to the paired controls group, when they have to detect stimuli that are physically different than a standard one. More precisely, a major interest of this study is that, due to ERP excellent temporal resolution, we will be able to examine the time course of a hypothetical deficit presented by MDMA users when they have to detect rare stimuli: if the N200 component is impaired, this could reflect attentional deterioration, whereas a P3b impairment (with an intact N200) would reflect a later decisional deficit.

The use of the oddball paradigm has also another potential interest. Indeed, converging evidence indicates that a network of brain regions responds to stimuli that are contextually novel, such as N2 and P3 components generated by oddball designs. This network includes areas in the prefrontal cortex, cingulate gyrus medial temporal cortex and the hippocampus (e.g. Ranganath and Rainer, 2003; Horn et al., 2003). Moreover, it is nowadays largely accepted that ERP components reflect postsynaptic effects of neurotransmitters like glutamate and GABA and indirect modulating effects from neuromodulators like acetylcholine, noradrenaline, dopamine and serotonine (Frodl-Bauch et al., 1999). More precisely, several studies showed that ERP components generated in oddball designs (such as N2 and P3b) could be modulated by serotoninergic (e.g., Hansenne and Ansseau, 1999) and dopaminergic (e.g., Sohn et al., 1998) influences. Then: (1) as serotonin and dopamine decreases have been reported in MDMA users (Buchert et al., 2001; Volkow et al., 2001); and (2) as the $\mathrm{N} 2$ and the $\mathrm{P} 3 \mathrm{~b}$ components are submitted to serotonergic and dopaminergic influences, the oddball design used in the present study could then allow us to show the neurotoxic effect of MDMA consumption by means of the potential modulation of these components.

Finally, neutral and emotional faces were used in the present study as frequent and deviant stimuli. We know that emotions are important in our everyday life in social interaction, adjustment and coordination of our behavior with respect to others. Failure to adequately communicate one's emotional and motivational state and/or adequately perceive the internal state of others is likely to result in interpersonal and personal problems. We used then emotional faces in order to increase the ecological validity of our stimuli. ${ }^{1}$

\footnotetext{
${ }^{1}$ Another interest of using emotional visual faces stimuli is that waves in response to those stimulations are well known: P100/N100 complex has a proposed striate and extrastriate origin and is typically described in visual ERP studies reflecting primary visual analyses (Gomez et al., 1994; Heinze et al., 1994), VPP/N170 are usually considered as face-specific (Bentin et al., 1996, 1999; Rossion et al., 1999; Campanella et al., 2002b).
} 
Overall, MDMA is supposed to cause body and brain damages. However, at the present time, there is no consensus on the effects generated by this substance on the human brain and cognition. Even so, the use of ecstasy seems to cause neurotoxic damage to the serotonergic and dopaminergic neurons. By means of an ERP oddball paradigm, we hope to provide empirical data showing whether the detection of new rare stimuli is processed differently by MDMA abusers as compared to control non-abusers. Moreover, we think it relevant to investigate where the differences occurring in a group of ecstasy users originated at the cognitive level. Due to their excellent temporal resolution, event-related potentials (ERPs) allow us to explore the temporal course of the various stages implied in a cognitive function (Rugg and Coles, 1995). This would help us to define where did originate some differences in the information-processing system (e.g., Campanella et al., 2002, 2004).

\section{Experiment}

\subsection{Subjects}

ERPs were recorded in 14 ecstasy users (MDMA users) and 14 paired normal subjects (CONTROLS). MDMA users were recruited via our acquaintances. Both groups had to answer a questionnaire where they were asked to list the different drugs they are consuming or they used to consume, quantities and frequencies, when they started and for how long they stopped using drug(s) if they did stop. We did not reveal that we were looking for subjects using MDMA only. At the beginning we wanted to select people only consuming MDMA. This was partially possible as many MDMA users also use cannabis. As a matter of fact, we matched subjects by using their age: CONTROLS ages ranged from 23 to 30 (mean: 26; S.D.: 1.7) and MDMA users ages ranged from 20 to 32 (mean: 25; S.D.: 3.1); the scores of the 13-items Beck Inventory Depressive Scale (mean: 2.79; S.D.: 3.24 and mean: 3.14; S.D.: 2.45 for CONTROLS and MDMA users, respectively); the Spielberger Anxiety Inventory-Trait and State (mean: 42.57; S.D.: 9.25 and mean: 41.5; S.D.: 9.84 for CONTROLS and MDMA users, respectively); and their cannabis consumption. We are aware that cannabis consumption could influence cognition and cognitive ERPs. However, the literature on the use of cannabis and its effect on cognitive processes is not clear: some studies found attentional and memory impairments (Solowij et al., 2002), even if these ones are reversible and related to recent cannabis exposure (Pope et al., 2001). Some other studies report unimpaired cognition (e.g., Lyketsos et al., 1999). Then, in order to avoid any problem, we paired control and MDMA subjects on smoking and no-smoking cannabis. Finally, it is also interesting to note that, in our MDMA users group, the MDMA consumption ranged from 13 to 350 pills (mean: 143.07; S.D.: 109.12: range 13-350, in a period going from 1 to 10 years).

Table 1 summarizes all subjects' characteristics. A paired $t$-test did not show any difference between the two groups for the age $\left(t_{(13 \text { d.f. })}=1.829\right.$; NS $)$, the Beck scale $\left(t_{(13 \text { d.f. })}=-0,285 ; \mathrm{NS}\right)$, the STAI-S scale $\left(t_{(13 \text { d.f. })}=1.506 ; \mathrm{NS}\right)$ and the STAI-T scale $\left(t_{(13 \text { d.f. })}=0.261 ; \mathrm{NS}\right)$. All subjects were right-handed men. 
Table 1

MDMA and CONTROLS means and standard deviation (S.D.) of age, Beck, STAI-E, STAI-T results

\begin{tabular}{llllllll}
\hline AA & $N$ & $\begin{array}{l}\text { Mean } \\
\text { age (S.D.) }\end{array}$ & Pills & On/off & Beck & STAI-E & STAI-T \\
\hline MDMA & 14 & $24.64(3.13)$ & $143.07(109.12)$ & On $=6$, off $=8$ & $3.14(2.45)$ & $41.50(4.93)$ & $41.50(9.84)$ \\
CONTROLS & 14 & $25.57(1.74)$ & 0 & & $2.79(3.24)$ & $43.93(5.44)$ & $42.57(9.26)$ \\
\hline
\end{tabular}

For MDMA, number of pills taken and consumption still going on (on) or stopped (off).

\subsection{Recordings}

Electroencephalogram (EEG) recordings were performed with 32 electrodes mounted in an electrode Quick-Cap. Electrode positions included the standard 10-20 International System locations and intermediate positions. Recordings were made with a linked mastoid physical reference. The EEG was amplified by battery-operated SYNAMPS amplifiers with a gain of 30,000 and a band-pass of 0.01-100 Hz. The impedance of all electrodes was kept below $20 \mathrm{k} \Omega$. EEG was continuously recorded (sampling rate $500 \mathrm{~Hz}$, Neuroscan) and trials contaminated by EOG artifacts were eliminated off-line. Epochs beginning $150 \mathrm{~ms}$ prior to stimulus onset and continuing for $850 \mathrm{~ms}$ were created. Codes synchronized with stimulus delivery were used to average selectively the epochs associated with different stimulus types. Two parameters were coded for every stimulus: (1) the type of the stimulus (rare HAPPY; rare FEAR; and in order to have the same number of averaged frequent stimuli, only the frequent stimuli preceding the deviant ones); and (2) the response type (keypress for deviant stimuli, no keypress for frequent ones). This coding allowed us to compute different averages of ERP target stimuli. These averages were made for each subject individually. Data were filtered with a $30 \mathrm{~Hz}$ lowpass filter.

\subsection{Stimulation and procedure}

Stimuli consisted in four faces ( 2 women and 2 men) with neutral, happy and fearful expressions. These faces were selected from the highly standardized set of pictures of Ekman \& Friesen series (1976) (actors PE, JJ, MO and PF).

Subjects were confronted with a total of 16 blocks (four different blocks repeated four times each). One block was defined by 100 stimuli. For instance, block 1 used PE face and presented 84 frequent stimuli with neutral expression and 16 RARE stimuli, 8 HAPPINESS and 8 FEAR.

During the ERPs recording, subjects sat on a chair in a dark room with their head restrained in a chin rest. Their head was placed $1 \mathrm{~m}$ from the screen and the stimuli were $6 \mathrm{~cm}$ horizontal and $8 \mathrm{~cm}$ vertical, subtending a visual angle of $3^{\circ} \times 4^{\circ}$. The order of the 16 blocks varied across subjects. The screen background was black. Faces were presented for $500 \mathrm{~ms}$. A black screen was displayed as intertrial interval, lasting randomly between 1300 and $1600 \mathrm{~ms}$, but subjects had $1500 \mathrm{~ms}$ to answer since stimulation onset. The participants had to point out as quickly as possible the occurrence of a deviant stimulus by pressing a mouse button with their right index finger. 


\subsection{Data analysis}

Each ERP component (N100, P100, N170, VPP, N200, P3a, and P3b) was manually identified on the basis of its latency range, topographical distribution and reproducibility from the channels: Oz, O1, O2, Cz, C3, C4, Pz, P3, P4, P7, P8, Fz, F3, F4, F7, F8. Moreover, by means of ASA 3.0 (ANT Software), a dipole analysis was performed on the grand-average ERP components specifically generated by the oddball design (i.e., N2/P3a complex and P3b component) in order to investigate the influence of MDMA consumption on their generators. A spherical three-layer head model was used.

\subsection{Statistical analyses}

As performance was at $98 \%$ correct, only correct response latencies were statistically analyzed with Systat $5.1^{\circledR}$. At selected electrodes, individual peak amplitudes and individual maximum peak latencies could be obtained separately for the ERPs resulting from the subtraction of waveforms evoked by standard and deviant stimuli. These values were tested using repeated-measures of analyses of variance (ANOVAs). When appropriate and in order to compensate the "non-sphericity" in repeated-measures ANOVA, the Greenhouse-Geisser adjustment of degrees of freedom was used to avoid increasing type I family-wise error rate.

\section{Results}

\subsection{Behavioral data}

Two main results can be observed: (1) as already shown in the literature (Campanella et al., 2004) MDMA stimuli are detected faster as compared to MDMA stimuli as confirmed by an ANOVA which shows a main stimulus effect $\left(F_{1,26}=56,634 ; P<.0001\right)$. This effect is observed in both groups (MDMA stimuli mean latencies for MDMA: $386 \mathrm{~ms}$; S.D.: 36.38; for MDMA users: 410 ms; S.D.: 46.64 and MDMA stimuli for CONTROLS: 416 ms; S.D.: 35.72; for MDMA users 442 ms; S.D.: 44.85); (2) MDMA users are slower than CONTROLS when they have to detect rare stimuli (mean of HAPPY and FEAR STIMULI), paired Student's $t$-tests show that this effect is significant when comparing HAPPY stimuli detections $\left(t_{(13 \text { d.f. })}=-2.903 ; P=.012\right)$ and FEAR stimuli detections $\left(t_{(13 \text { d.f. })}=-3.713 ; P=.003\right)$.

It is also interesting to note that the MDMA users implied in this experiment have a great variance in their frequency and quantity of ecstasy consumption. In order to give further support to the idea that the decrease showed by MDMA users in the detection of rare stimuli was specifically due to MDMA consumption, we performed a paired Student's $t$ test comparing the response latencies of high-MDMA users ( $>100$ pills; mean of 232 , S.D.: $79 ; n=7$ ) versus low-MDMA users ( $<100$ pills; mean of 56 , S.D.: $31 ; n=7$ ). It was shown that high users had significant higher response latencies than low ones (mean high: $445 \mathrm{~ms}$, S.D.: 37.295; mean low: $408 \mathrm{~ms}$, S.D.: 45.453; $\left.t_{(6 \text { d.f. })}=-2.607 ; P=.04\right)$. Interestingly, these two subgroups also showed the above mentioned difference between 
HAPPY and FEARFUL stimuli (low-HAPPY: $425 \mathrm{~ms}$, S.D.: 51.627; FEAR: $391 \mathrm{~ms}$, S.D.: $40.526, t_{(6 \text { d.f. })}=5.313, P=.002$; high-HAPPY: 459 ms, S.D.: 31.559 , fear: 429 ms, S.D.: $\left.47.063, t_{(6 \text { d.f. })}=2.789, P=.032\right)$.

\subsection{Neurophysiological data}

Fig. 1 shows the grand-average waveforms obtained in response to frequent stimuli. As classically observed in the ERP face literature, we found for both groups: (1) a bipolar P100/N100 complex, recorded around $110 \mathrm{~ms}$ at occipital and central sites, which has a proposed striate and extrastriate origin and is typically described in visual ERP studies reflecting primary visual analyses (Gomez et al., 1994; Heinze et al., 1994); and (2) a bilateral N170 recorded at occipito-temporal sites (P7 and P8) and reversing polarity at $\mathrm{Cz}$ with positive counterpart being called the vertex positive potential (VPP, Campanella et al., 2000). Those two components (VPP/N170) are usually considered as face-specific (Bentin and Deouell, 2000), even if this is still matter of debate (Rossion et al., 2003). Note that if we observed those four components in both groups, they did not behave in the same way for N170 (from channels P7, P8), which amplitude is reduced in the MDMA group as shown by the ANOVAs performed for the between-subjects effect
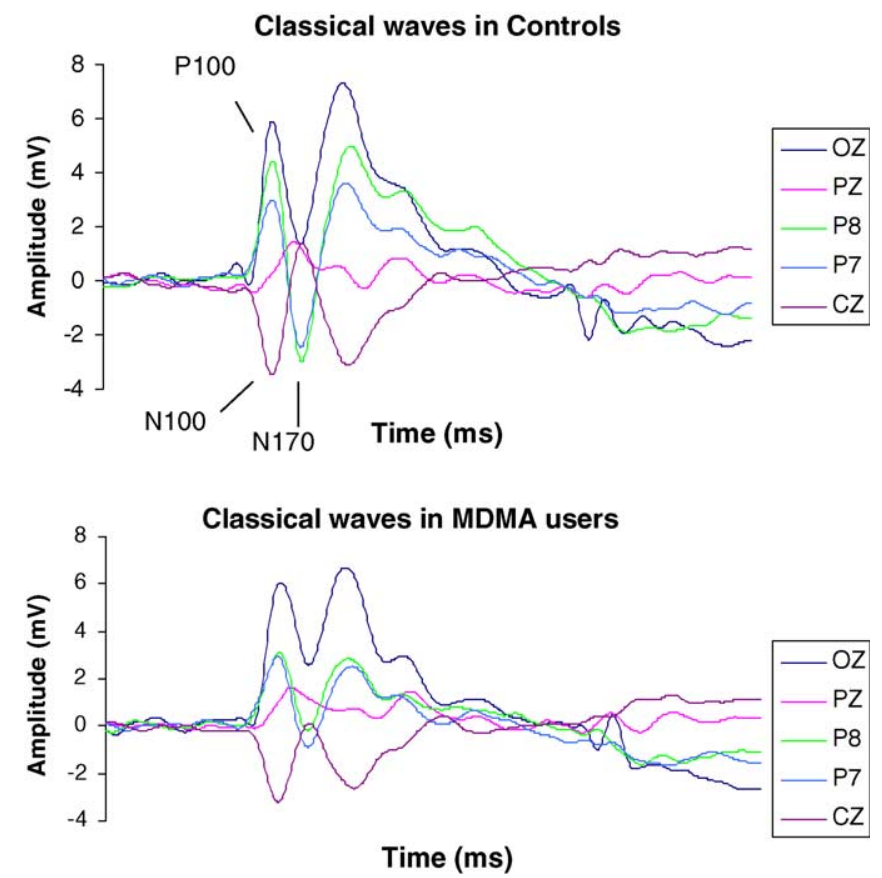

Fig. 1. Classical ERP waves obtained for faces: the P100/N100 complex recorded at centro-occipital sites $(\mathrm{Cz}$, $\mathrm{Oz}$ ), and the N170 recorded at bilateral occipito-temporal sites (P7, P8). Please note the absence of the P300 component $(\mathrm{Pz})$, as no response was required for frequent stimuli; and the lower amplitude of the N170 recorded for MDMA users. 
Table 2

Mean latencies and amplitudes of classical face-ERP waves for frequent stimuli

\begin{tabular}{lllllll}
\hline Components & Electrodes & \multicolumn{2}{c}{ Mean amplitudes $(\mathrm{mV})$ for } & & \multicolumn{2}{c}{ Mean latencies (ms) for } \\
& & CONTROLS & MDMA & & CONTROLS & MDMA \\
\hline P100 & OZ & 5.87 & 6.07 & & 112 & 121 \\
N100 & CZ & -3.50 & -3.25 & & 114 & 122 \\
N170 & P7 & -2.91 & $-1.59^{*}$ & & 155 & 164 \\
& P8 & -3.58 & $-0.72^{*}$ & & 157 & 156 \\
\hline
\end{tabular}

* Significant at $P=.005$.

$\left(F_{1,26}=9881 ; P=.004\right)$ (Table 2$)$. Other components did not show any significant differences.

Fig. 2 shows that regular oddball components were observed in both CONTROLS and MDMA groups for the rare minus frequent stimuli condition. Indeed, a negativity was maximally recorded around $230 \mathrm{~ms}$ at $\mathrm{Oz}$, with a positive counterpart recorded around $250 \mathrm{~ms}$ at Fz. The waveforms and topography lead us to conclude that this bipolar complex is probably identical to the well-described N2/P3a complex, observed for instance by Halgren and Marinkovic (1995) or Campanella et al. (2002). Table 3(a) and (b) shows the mean amplitudes and latencies observed for both components (N2/P3a and P3b) in

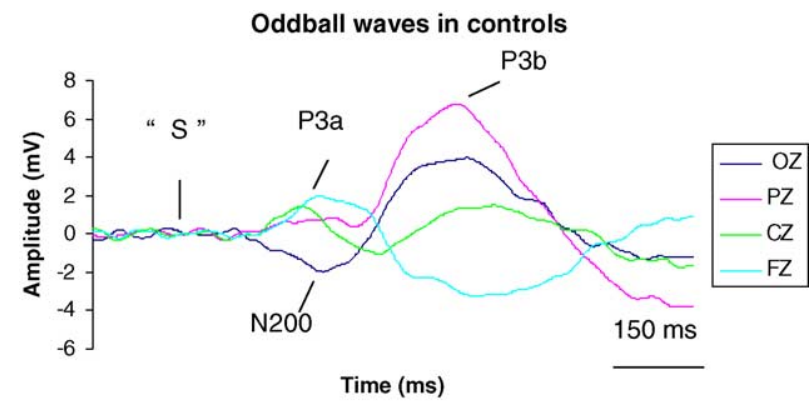

Oddball waves in MDMA users

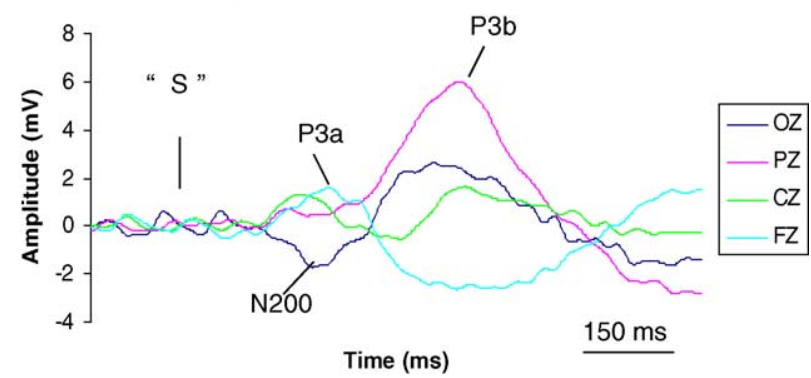

Fig. 2. Classical oddball waves, N2/P3a and P3b, recorded in both groups on $\mathrm{Oz}, \mathrm{Pz}$ and Fz, and obtained by means of the subtraction FREQUENT stimuli - RARE stimuli. 
Table 3

(a) Mean amplitudes and (b) mean latencies for the "oddball" components in RARE-FREQUENT, HAPPY and FEAR stimuli conditions

\begin{tabular}{lllllll}
\hline Components & Electrodes & RARE-FREQUENT stimuli & $\frac{\text { HAPPY stimuli }}{\text { CONTROLS MDMA }}$ & CONTROLS MDMA & CONTROLS MDMA
\end{tabular}

(a) Mean amplitudes

$\begin{array}{llrrrrrr}\text { N200 } & \text { O1 } & -3.88 & -3.67 & -4.16 & -3.46 & -4.42 & -3.80 \\ & \text { O2 } & -3.82 & -3.51 & -3.52 & -4.00 & -4.66 & -3.75 \\ \text { P3a } & \text { F3 } & 2.88 & 2.10 & 3.21 & 2.04 & 2.96 & 2.53 \\ & \text { F4 } & 2.94 & 2.46 & 3.21 & 2.43 & 3.02 & 2.80 \\ \text { P3b } & \text { P3 } & 5.46 & 5.16 & 5.50 & 5.08 & 5.98 & 6.42 \\ & \text { P4 } & 5.92 & 4.91 & 6.03 & 5.14 & 5.70 & 5.28\end{array}$

(b) Mean latencies

\begin{tabular}{llllllll} 
N200 & O1 & 230 & 246 & $252^{*}$ & 250 & $225^{*}$ & 245 \\
& O2 & 230 & 247 & $251^{*}$ & 250 & $225^{*}$ & 250 \\
P3a & F3 & 238 & 253 & 250 & 248 & 234 & 252 \\
& F4 & 237 & 247 & 250 & 249 & 235 & $467^{\prime}$ \\
P3b & P3 & $434^{\prime \prime}$ & $465^{\prime \prime}$ & $457^{\prime}$ & $483^{* *}$ & $407^{\prime *}$ \\
& P4 & $434^{\prime \prime}$ & $468^{\prime \prime}$ & $448^{\prime}$ & $478^{* *}$ & $419^{\prime}$ & $465^{* *}$ \\
\hline
\end{tabular}

Threshold of significance for data with * significant at $P=.005 ;{ }^{\prime}$ significant at $P=.001 ;{ }^{* *}$ significant at $P=.001$;

" significant at $P=.02$.

response to rare stimuli (happy and fear). N2 component was maximally recorded at the occipital sites $(\mathrm{O} 1, \mathrm{O} 2), \mathrm{P} 3 \mathrm{a}$ at the frontal sites $(\mathrm{F} 3, \mathrm{~F} 4)$ and $\mathrm{P} 3 \mathrm{~b}$ at the parietal sites ( $\mathrm{P} 3$ and P4).

\subsection{General "RARE-FREQUENT" comparison}

In the RARE minus FREQUENT condition (mean of HAPPY and FEAR stimuli), ANOVAs $2 \times 2$ with group as between factor (MDMA versus CONTROLS), and lateralization (LEFT versus RIGHT) as within factor did not show significant result for N2 and P3a components. However, P3b latencies results show a main group effect (and no effect of lateralization nor interaction): MDMA users show delayed latencies as compared to CONTROLS $\left(F_{1,26}=4567 ; P=.042\right)$; amplitudes are not different.

\subsection{MDMA versus CONTROLS for HAPPY and FEARFUL stimuli}

An ANOVA $2 \times 2$ with group as between factor (MDMA versus CONTROLS), and lateralization (LEFT versus RIGHT) as within factor, did not show any difference for the N2 and P3a waves (HAPPY in CONTROLS versus HAPPY in MDMA; FEAR in CONTROLS versus FEAR in MDMA). An identical analysis was performed on P3b latencies and amplitudes. There was no difference (in amplitudes and latencies) when HAPPY stimuli were considered. However, when P3b latencies are considered, a main effect of group on FEAR condition emerged (and no effect of lateralization nor 
interaction): MDMA users show delayed latencies as compared to CONTROLS for FEAR stimuli $\left(F_{1,26}=6410 ; P=.018\right)$.

\subsection{HAPPY versus FEAR stimuli inside both groups}

We also compared waves in response to HAPPY versus FEAR stimuli per groups (HAPPY versus FEAR in CONTROLS; HAPPY versus FEAR in MDMA). ANOVAs $2 \times 2 \times 2$ with group as between factor (MDMA versus CONTROLS), lateralization (LEFT versus RIGHT) and emotion (HAPPY versus FEAR) as within factors were performed. Results suggest:

- On amplitudes:

- An emotion $\times$ lateralization effect (mean FEAR left: 6.20; FEAR right: 5.50; HAPPY left: 5.29; HAPPY right: 5.59$)\left(F_{1,26}=6404 ; P=.018\right)$ for the P3b component.

- On latencies:

- An emotion effect for FEAR (mean: $237 \mathrm{~ms}$ ) versus HAPPY (mean: 251) $\left(F_{1,25}=4572 ; P=.042\right)$ for the N200 component: however, paired Student's $t$-tests revealed that this difference was significant in normal controls (FEAR: $226 \mathrm{~ms}$; HAPPY: $\left.252 \mathrm{~ms} ; t_{(13 \text { d.f. })}=3.25 ; P=.006\right)$ but not for MDMA users (FEAR: $248 \mathrm{~ms}$; HAPPY: $\left.250 \mathrm{~ms} ; t_{(13 \text { d.f. })}=0.2 ; \mathrm{NS}\right)$.

- An emotion effect for FEAR (mean: 438$)$ versus HAPPINESS (466) $\left(F_{1,26}=14,107\right.$; $P=.001$ ) for the P3b component in both groups (normal: FEAR: $414 \mathrm{~ms}$; HAPPY: $453 \mathrm{~ms}$; MDMA: FEAR: $460 \mathrm{~ms}$; HAPPY: $484 \mathrm{~ms}$ ).

- An emotion $\times$ lateralization effect (mean FEAR left: 434; FEAR right: 442; HAPPY left: 470; HAPPY right: 463$)\left(F_{1,26}=6350 ; P=.018\right)$ for the P3b component.

- A main effect of group: MDMA users show delayed latencies as compared to CONTROLS (mean latencies for MDMA: 471 and for CONTROLS: 433) $\left(F_{1,26}=6391 ; P=.018\right)$ for the P3b component.

\subsection{Dipole analysis}

As suggested above, converging evidence indicates that a network of brain regions responds to stimuli that are contextually novel, such as N2 and P3 components generated by oddball designs. This network includes areas in the prefrontal cortex, cingulate gyrus, medial temporal cortex and the hippocampus (e.g. Ranganath and Rainer, 2003; Horn et al., 2003). In the present study, we performed a dipole analysis by using ASA 3.0 (ANT Software) in order to investigate the neural generators evoking N2/P3a and P3b components (on grand-averages waveforms). As can be seen in Table 4, an interesting dipole fit solution was defined for the N2/P3a complex, generated in normal controls, by 3 fixed dipoles including the anterior (BA 32) and the ventral (BA 25) cingulate gyrus. The cingulate gyrus is well known to be involved in attention and emotional processing (Lane et al., 1997), as it shows, for instance, a significant decrease in depression (suggesting a fundamental role in the regulation of mood; see Bench et al., 1993), and its lesion provokes akinetic mutism, a condition associated with blunting of emotional experience (Damasio and Van Hoesen, 1983). Concerning the P3b component, it is suggested that the best dipole 
Table 4

Synthesis of the dipole analysis in MDMA and CONTROL groups for the oddball components (N2/P3a, P3b) by using a three-layer spherical head model for each individual subjects

\begin{tabular}{|c|c|c|c|c|c|c|c|}
\hline & & $x$ & $y$ & $z$ & $\begin{array}{l}\text { Best fit } \\
\text { latency (ms) }\end{array}$ & $\begin{array}{l}\text { Mean } \\
\text { magnitude (nAm) }\end{array}$ & GOF (\%) \\
\hline Control subjects & BA 32 & 50 & 0 & 16 & & & \\
\hline \multirow[t]{2}{*}{$\mathrm{N} 2 / \mathrm{P} 3 \mathrm{a}$} & BA 25 right & 10 & 8 & -8 & 253 & $870^{*}$ & $80^{* * *}$ \\
\hline & BA 25 left & 10 & -8 & -8 & & & \\
\hline MDMA users & BA 32 & 50 & 0 & 16 & & & \\
\hline \multirow[t]{2}{*}{$\mathrm{N} 2 / \mathrm{P} 3 \mathrm{a}$} & BA 25 right & 10 & 8 & -8 & 254 & 538 & 73 \\
\hline & BA 25 left & 10 & -8 & -8 & & & \\
\hline Control subjects & BA 9 right & 21 & 43 & 39 & & & \\
\hline \multirow[t]{3}{*}{$\mathrm{P} 3 \mathrm{~b}$} & BA 9 left & 21 & -43 & 39 & 468 & $5056^{*}$ & $83^{* * * *}$ \\
\hline & SMA right & 8 & 4 & 56 & & & \\
\hline & SMA left & 8 & -4 & 56 & & & \\
\hline MDMA users & BA 9 right & 21 & 43 & 39 & & & \\
\hline \multirow[t]{3}{*}{$\mathrm{P} 3 \mathrm{~b}$} & BA 9 left & 21 & -43 & 39 & 452 & 4061 & 74 \\
\hline & SMA right & 8 & 4 & 56 & & & \\
\hline & SMA left & 8 & -4 & 56 & & & \\
\hline
\end{tabular}

Threshold of significance for data with ${ }^{*}$ significant at $P<.05$, with ${ }^{* *}$ significant at $P=.005$ and with ${ }^{* * *}$ significant at $P=.007$.

solution is represented by two pairs of dipoles situated in the supplementar motor area (SMA) and the prefrontal cortex (BA 9): this is in perfect agreement with the fact that this P3b component is generally referred to several psychological concomitants, such as decision-making and premotor response preparation (Halgren et al., 1994).

However, it was shown that when these dipolar configurations are used in MDMA abusers, they present: (1) a lesser efficiency to account for N2/P3a complex (the explained residual variance is worse than for normal controls: $\left.t_{(13 \text { d.f. })}=3.425 ; P=.005\right)$; (2) a lower activity to generate $\mathrm{N} 2 / \mathrm{P} 3 \mathrm{a}$ component in the anterior and the right ventral cingulate cortex $\left(t_{(13 \text { d.f. })}=2.314 ; P=.038\right)$; and (3) identical results for the P3b component (explained variance: $t_{(13 \text { d.f. })}=3.617 ; P=.007$; magnitude: $\left.t_{(13 \text { d.f. })}=2.549 ; P=.024\right)$.

\subsection{Summary of results}

At the behavioral level, it is shown that fear is detected faster than happiness in both groups of subjects. However, CONTROLS are globally faster than MDMA users to detect rare stimuli, and high-MDMA users (consumption of more than 100 pills) implied longer response latencies than low ones.

The ERP data suggest that, on classical waves, only MDMA N170 amplitudes are reduced as compared to CONTROLS. Moreover, when oddball components are considered: (1) the N200 component, which is involved in attention orienting associated to the detection of stimulus novelty (e.g. Campanella et al., 2002), shows in both groups a higher amplitude when fearful expressions are detected; however, it also suggests shorter latencies for fearful rare stimuli but only for normal controls; (2) the P3b component which reflects later conscious, decisional and premotor response-related stages (e.g. Bentin et al., 
N2 and P3b effect on controls
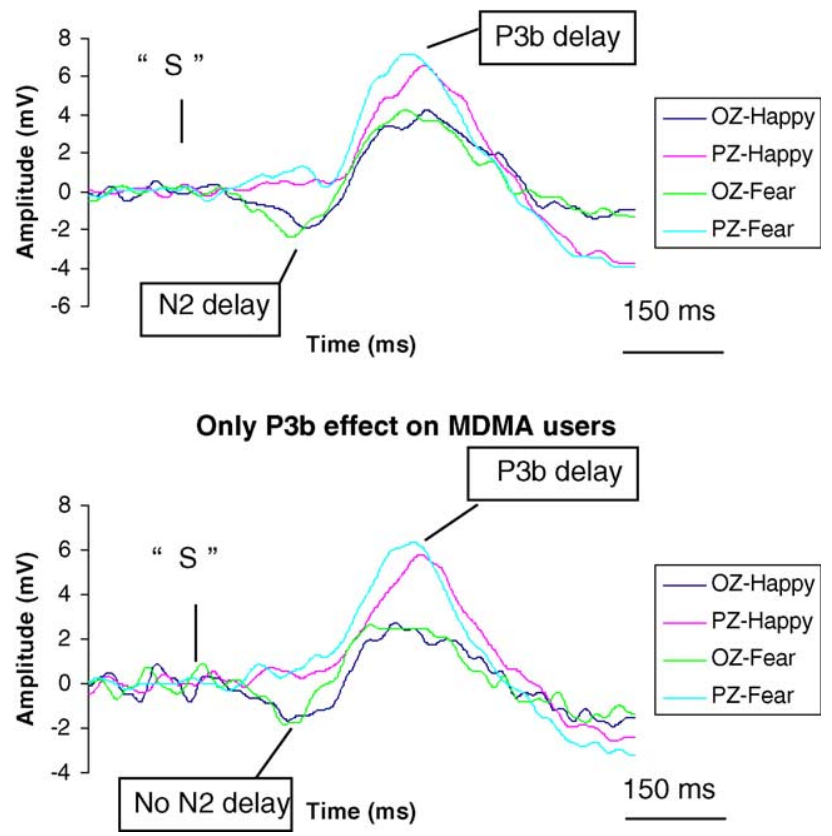

Fig. 3. Comparison of HAPPY and FEAR rare stimuli $(\mathrm{Oz}, \mathrm{Pz}, \mathrm{Fz})$. In normal controls, a delay could be observed as for the $\mathrm{N} 2$ than for the P3b component. This delay was restricted to the P3b in MDMA users.

1999), is altered in MDMA abusers patients as compared with normal controls, as delayed latencies for the detection of rare stimuli are observed (see Fig. 3 for illustration).

Finally, a dipole analysis was performed in order to define the generators involved in N2/P3a complex and P3b component. An interesting dipole fit solution was defined for the $\mathrm{N} 2 / \mathrm{P} 3 \mathrm{a}$ complex by dipoles situated in the cingulate gyrus, whereas these dipoles were situated in the SMA and the prefrontal cortex for the P3b component. However, it was shown that these same dipole solutions were less efficient (worse explained variance) and presented a lower magnitude when MDMA abusers were considered.

\section{Discussion}

Recreational drugs are generally consumed because of their psychotropic effects, but many of them also have systemic effects as well as adverse effects on the central and peripheral nervous system. Indeed, MDMA use may result in such systemic effects as cardiac dysrythmias, disseminated intravascular coagulation, hyperthermia, acute renal failure and hepatic abnormalities (Neiman et al., 2000). Moreover, MDMA possesses both central nervous system stimulant effects and hallucinogenic properties, the serotonergic effects being more prominent than the dopamine-releasing effects (Steele et al., 1994). The fact that these neurochemical properties automatically lead MDMA users to present 
cognitive deficits is still matter of debate. In the present study, MDMA users and paired healthy non-abusers were confronted during an ERP recording to a visual oddball task.

As facial expressions were used in the present experiment, a first step consists in investigating whether conventional ERP components evoked by faces could be observed (see for instance, Jeffreys, 1989; Bentin et al., 1996; Rossion et al., 1999; Campanella et al., 2000). Complexes as P100/N100, N170 synchronized with the VPP were then clearly identified in response to our facial stimuli. Moreover, as we used an oddball design, we can observe that the traditional ERP waves obtained by subtracting FREQUENT stimuli from RARE ones, i.e. the N2/P3a complex and the P3b (see for instance, Campanella et al., 2002), are also observable in both groups of our study.

Results suggest that CONTROLS as well as MDMA users showed faster responses to fearful faces expressions as compared to happy ones; however, MDMA are globally slower than CONTROLS to detect rare stimuli (mean of HAPPY and FEAR stimuli).

This was neurophysiologically indexed as follows: on the one hand, we observed-in normal controls-a posterior N2 component, reflecting the degree of voluntary attention related to visual information-processing during a target detection task (Campanella et al., 2002; Halgren et al., 1994). ${ }^{2}$ The N2 was both enhanced in amplitude and of shorter latency for fearful stimuli. As facial muscles are differently involved in the production of happy and fearful expressions (Ekman and Friesen, 1976), it could be that the physical differences between neutral and fearful faces are more important than physical differences between neutral and happy ones. This could lead subjects to detect more quickly the physical differences related to the fearful facial expression, providing support for a critical role of this fear system in fast adaptive behavior to threats (Whalen et al., 1998). A principal role is suggested for amygdale, which could play some role in tuning the visual system to become more sensitive to threat cues by means of efferent projections to primary sensory areas (Campanella et al., 2002; Davidson and Irwing, 1999; Ledoux, 1995). The greater attentional resources devoted to fearful faces can be considered as adaptive, as it is important to correctly identify fear in order to understand what is at stake and how to cope with it.

On the other hand, we also obtained a parietal P3b component, which was functionally related to several psychological concomitants (such as decision-making, premotor response preparation, context updating). This component showed greater amplitude and an earlier peak latency for fearful faces than for happy ones, indicating a complete consistency between behavioral and neurophysiological data. Indeed, a behavioral delay was obtained for response latencies, suggesting that fearful stimuli were detected faster than happy ones.

The situation is thus quite clear for normal controls, and it has already been described as such in the literature (see for instance, Campanella et al., 2004): due to higher physical

\footnotetext{
2 The N2/P3a complex is generally described as representing an "attentional orienting complex" (Halgren et al., 1994; Campanella et al., 2002). More precisely, the N2 component generally refers to the switch of attention needed to take a new information into account (e.g., Campanella et al., 2002), whereas the P3a component is more sensitive to the degree of novelty of the new information (e.g., Suwazano et al., 2000). In the present study, all rare stimuli have the same probability of occurrence, sharing then the same level of "novelty" among the train of standard stimuli. As a consequence, we do not wait for P3a modulations, and this explains why only N2 results will be reported in the present study.
} 
differences, fear stimuli are detected faster than happy ones, and ERP correlates of this behavioral effect are defined by a delay in the P3b component (reflecting the responserelated stage), that originated in the greater attentional resources (reflected by a N2 of shorter latency onset) devoted to fearful faces. ${ }^{3}$

However, the situation is quite different when MDMA users were considered. First, it was shown that MDMA users implied longer latencies than normal controls to detect rare stimuli. This was neurophysiologically indexed by a delayed P3b component (mean latencies for MDMA: $471 \mathrm{~ms}$ and for CONTROLS: $433 \mathrm{~ms}$ ). Second, even if fearful stimuli were detected faster than happy ones in both groups, it is suggested in the present study that this effect did not originate at the attentional level in MDMA users. Indeed, statistical results showed that there was no latency effect on the N2 component when happy and fearful faces are compared in MDMA group (FEAR: $248 \mathrm{~ms}$; HAPPY: $250 \mathrm{~ms}$ ), but only an effect on the P3b component (FEAR: $460 \mathrm{~ms}$; HAPPY: $484 \mathrm{~ms})$.

In other words, the present data suggest that, in normal controls, the behavioral effect that consists in detecting more precociously fearful faces than happy ones originates at the attentional level of the information-processing system (delayed N2 extending to delayed P3b), whereas it was postponed to the decisional level in MDMA users (only delayed P3b). We suggest that this difference found its origin in MDMA neurotoxic effect leading to serotonin exhaustion (Audenaert, 2003), and that this neurotoxicity particularly affects attentional processes. Indeed: (1) MDMA induced a decrease in serotonergic activities (e.g., Buchert et al., 2001); (2) the attentional N2 component is generated by a distributed neural network including the cingulate gyrus, and it could be modulated by serotonergic influences (Hansenne and Ansseau, 1999); and (3) if we consider the dipole analysis performed in the present study, we can observe that, in normal controls, dipoles situated in the cingulate gyrus explained a great part of the residual variance of the N2/ P3a component, whereas, in MDMA users, these same dipoles present a lesser magnitude and a worse explained variance. As a consequence, we put forward the hypothesis that the consumption of MDMA has produced serious neurotoxic effects by affecting serotonergic activities, and that this deficit causes attentional deficits in MDMA users (neurophysiologically indexed by the absence of effect on the $\mathrm{N} 2$ component). This seems to us particularly important, as previous studies investigating the effect of MDMA consumption on cognition have been mainly focused on impairments for different kinds of memory, central executive functions, reasoning and semantic recognition (Montoya et al., 2002 for review). In the present study, it was suggested by means of ERPs that the cognitive deficits due to MDMA abuse could be due to an earlier deficit situated at the attentional level of the information-processing system. Note that this attentional interpretation could also account for the fact that normal controls are faster to detect deviant stimuli than MDMA users. This was in perfect agreement with a recent study of McCardle et al. (2004), showing, at a behavioral level, that MDMA users are

\footnotetext{
${ }^{3}$ Please note that we also obtained an emotion $\times$ lateralization interaction in amplitudes and latencies for the $\mathrm{P} 3 \mathrm{~b}$ component. This interaction suggests that the P3b component is left-lateralized for the FEAR stimuli, but not for the HAPPY ones. This result is in perfect agreement with neuroimaging studies showing that fearful facial expressions generated higher left amygdala activities than happy ones (e.g., Morris et al., 1996, 1998).
} 
more easily distracted and are less efficient at focusing attention on complex tasks. The present study gives, at our knowledge, the first neurophysiological account for this phenomenon.

Nevertheless, we are aware that these results should be considered as preliminary, and that several points should be verified in further studies. First, the attentional deficit we evidenced in this study has been obtained by means of emotional facial expressions. We showed that, when confronted to an identical amount of physical differences (neutral versus fear), MDMA users show delayed attentional resources as compared to normal controls. Moreover, we showed that the N170, a bilateral occipito-temporal negativity, functionally related to the configural processing of the face (e.g., Bentin et al., 1996; Campanella et al., 2002b), has a lower amplitude in MDMA users. Then, it would be useful in future researches to delineate whether the deficit observed here in MDMA users-that could be defined as a deficit in the detection of physical differences-was specific to the emotional modality, and if it referred to a more general "face processing" impairment. Second, in the present study, we were confronted with MDMA abusers who are still consuming $(N=6)$ and to others who have stopped (from 1 to 11 months). As it has been suggested that neuronal recovery seems to occur over several months in rats but seems to be only partial in monkeys and primates (Ricaurte et al., 2000), it would be interesting to investigate the reversibility of the cognitive impairments due to MDMA consumption as well as the time course of this potential recovery. We should also note that in our MDMA sample we had a great variance in the amount of MDMA consumption (from 13 to 350 pills). Then, it would also be relevant to study the relative influence of high- versus lowdoses consumption on cognitive processes, keeping in mind that the frequency of use may also have a differential effect (it may be different to consume 10 pills in 1 year or 10 pills in one month). Third, it has been shown that women presented an increased susceptibility to the 5-HT-releasing effects of MDMA, so that equal doses of MDMA per kilogram body weight produced stronger responses in women compared to men (Liechti et al., 2001). With this in mind, the issue of gender was dealt by including only males in our study (as in Semple et al., 1999). However, as outlined by Kish (2002), it would be interesting to investigate whether gender differences could be evidenced when male and female MDMA abusers are confronted to cognitive tasks. Fourth, empirical evidence have been gathered showing that ecstasy polydrug users present different cognitive deficits from "specific" ecstasy users (e.g., Fox et al., 2002). This implies that future studies may use multiple control groups in order to define the specific cognitive deficits induced by the consumption of a specific drug.

To conclude, progress in preventing and treating drug misuse and addiction requires a fuller understanding of the significance of cognitive dysfunction in the onset and maintenance of drug-seeking behavior (Rogers and Robbins, 2001). An important step for this purpose is to provide convincing links between cognitive deficits and underlying changes in brain physiology. Current empirical data seem to show that substance abuse is likely to involve changes within multiple levels of the neurocognitive system. By using ERPs, the present study furnishes preliminary data suggesting that the use of MDMA could lead to attentional deficits, which may suspect more severe cognitive alterations. As suggested above, further studies are needed to improve the understanding of deleterious MDMA effect on human cognition. 


\section{Acknowledgments}

This study was performed thanks to the financial support of the Rodin Foundation. We also thank Veronica Gomez Kieffer for her help during ERP recordings, Marie Bronchart for English checking and John Polich for comments on an earlier version of the manuscript. The last author was supported by the Belgian fund of scientific research (FNRS).

\section{References}

Altman, H.J., Normile, H.J., 1998. What is the nature of the role of the serotonergic nervous system in learning and memory: prospects for development of an effective treatment strategy for senile dementia. Neurobiology of Aginging 9, 627-638.

Audenaert, K., 2003. Le rôle de la sérotonine dans le fonctionnement psychique. Editions Kluwer, Bruxelles. Benazzi, F., Mazzoli, M., 1991. Psychiatric illness associated with "ecstasy". Lancet 338, 1520.

Bench, C.J., Friston, K.J., Brown, R.G., Frackowiak, R.S., Dolan, R.J., 1993. Regional cerebral blood flow in depression measured by positron emission tomography: the relationship with clinical dimensions. Psychological Medicine 23, 579-590.

Bentin, S., Allison, T., Puce, A., Perez, E., McCarthy, G., 1996. Electrophysiological studies of face perception in human. Journal of Cognitive Neuroscience 8, 551-565.

Bentin, S., Mouchetant-Rostaing, Y., Giard, M.H., Echallier, J.F., Pernier, J., 1999. ERP manifestations of processing printed words at different psycholinguistic levels: time course and scalp distribution. Journal of Cognitive Neuroscience 11, 235-260.

Bentin, S., Deouell, L.Y., 2000. Structural encoding and identification in face processing: ERP evidence for separate mechanisms. Cognitive Neuropsychology 17, 35-54.

Brodkin, J., Malyala, A., Nash, J.F., 1993. Effect of acute monoamine depletion on 3,4-methylenedioxymethamphetamine-induced neurotoxicity. Pharmacology Biochemistry and Behavior 45, 647-653.

Buchert, R., Obrocki, J., Thomasius, R., Vaterlein, O., Petersen, K., Jenicke, L., Bohuslavizki, K.H., Clausen, M., 2001. Long-term effects of 'ecstasy' abuse on the human brain studied by FDG PET. Nuclear Medicine Communications 22, 889-897.

Byard, R.W., Gilbert, J., James, R., Lokan, R.J., 1998. Amphetamine derivative fatalities in South Australia. Is "ecstasy" the culprit? American Journal of Forensic Medicine and Pathology 19, 261-265.

Campanella, S., Hanoteau, C., Depy, D., Rossion, B., Bruyer, R., Crommelinck, M., Guerit, J.M., 2000. Right N170 modulation in a face discrimination task: an account for categorical perception of familiar faces. Psychophysiology 37, 796-806.

Campanella, S., Gaspard, C., Debatisse, D., Bruyer, R., Crommelinck, M., Guérit, J.M., 2002. Discrimination of emotional facial expression in a visual oddball task: an ERP study. Biological Psychiatry 59, 171186.

Campanella, S., Quinet, P., Bruyer, R., Crommelinck, M., Guérit, J.M., 2002b. Categorical perception of happiness and fear facial expressions: an ERP study. Journal of Cognitive Neuroscience 14, 210-227.

Campanella, S., Rossignol, M., Mejias, S., Joassin, F., Maurage, P., Debatisse, D., Bruyer, R., Crommelinck, M., Guérit, J.M., 2004. Human gender differences in an emotional visual oddball task: an ERP study. Neuroscience Letters 367, 14-18.

Chang, L., Grob, C.S., Ernst, T., Itti, L., Mishkin, F.S., Jose-Melchor, R., Poland, R.E., 2000. Effect of ecstasy [3,4methylenedioxymethamphetamine (MDMA)] on cerebral blood flow: a co-registered SPECT and MRI study. Psychiatry Research 98, 15-28.

Damasio, A.R., Van Hoesen, G.W., 1983. In: Heilman, K.M., Satx, P. (Eds.), Neuropsychology of Human Emotion. Guilford Press, New York.

Davidson, R.J., Irwing, W., 1999. The functional neuroanatomy of emotion and affective style. Trends in Cognitive Sciences 3, 11-21.

Deakin, J.F., 1998. The role of serotonin in panic, anxiety and depression. International Clinical Psychopharmacology $13,1-5$. 
Dowling, G.P., McDonough III, E.T., Bost, R.O., 1987. 'Eve' and 'ecstasy'. A report of five deaths associated with the use of MDEA and MDMA. Journal of the American Medical Association 257, 1615-1617.

Ekman, P., Friesen, W., 1976. Pictures of Facial Affect. Consulting Psychologists Press, Palo Alto, CA.

Fineschi, V., Centini, F., Mazzeo, E., Turillazzi, E., 1999. Adam (MDMA) and Eve (MDEA) misuse: an immunohistochemical study on three fatal cases. Forensic Science International 104, 65-74.

Fox, H.C., McLean, A., Turner, J.J., Parrott, A.C., Rogers, R., Sahakian, B.J., 2002. Neuropsychological evidence of a relatively selective profile of temporal dysfunction in drug-free MDMA ("ecstasy") polydrug users. Psychopharmacology 162, 203-214.

Frodl-Bauch, T., Bottlender, R., Hegerl, U., 1999. Neurochemical substrates and neuroanatomical generators of the event-related P300. Neuropsychobiology 40, 86-94.

Gamma, A., Buck, A., Berthold, T., Vollenweider, F.X., 2001. No difference in brain activation during cognitive performance between ecstasy (MDMA) users and controls: a [H215O]-PET study. Journal of Clinical Psychopharmacology 21, 66-71.

Gomez, C.M., Clarck, V.P., Luck, S.J., Fan, S., Hillyard, S.A., 1994. Sources of attention-sensitive visual eventrelated potentials. Brain Topography 7, 41-51.

Gouzoulis-Mayfrank, E., Daumann, J., Tuchtenhagen, F., Pelz, S., Becker, S., Kunert, H.J., Fimm, B., Sass, H., 2000. Impaired cognitive performance in drug free users of recreational ecstasy (MDMA). Journal of Neurology, Neurosurgery and Psychiatry 68, 719-725.

Halgren, E., Marinkovic, K., 1995. Neurophysiological networks integrating human emotions. In: Gazzaniga, M.S. (Ed.), The Cognitive Neuroscience. MIT Press, Cambridge, MA, pp. 1137-1151.

Halgren, E., Baudena, P., Heit, G., Clarke, J.M., Marinkovic, K., Chauvel, P., Clarke, M., 1994. Spatio-temporal stages in face and word processing. 2. Depth-recorded potentials in the human frontal and rolandic cortices. Journal of Physiology 88, 51-80.

Hansenne, M., Ansseau, M., 1999. P300 event-related potential and serotonin-1A activity in depression. European Psychiatry $14,143-147$.

Heinze, H.J., Mangun, G.R., Bruchert, W., Hinrichs, H., Scholtz, M., Münte, T.F., Gös, A., Scherg, M., Johannes, S., Hundeshagen, H., Gazzaniga, M.S., Hillyard, S.A., 1994. Combined spatial and temporal imaging of brain activity during selective attention in humans. Nature 372, 543-546.

Horn, H., Syed, N., Lanfermann, H., Maurer, K., Dierks, T., 2003. Cerebral networks linked to the event-related potential P300. European Archives of Psychiatry and Clinical Neuroscience 253, 154-159.

Jeffreys, D.A., 1989. A face-responsive potential recorded from the human scalp. Experimental Brain Research 78, 193-202.

Kish, S.J., 2002. How strong is the evidence that brain serotonin neurons are damaged in human users of ecstasy? Pharmacology Biochemistry and Behavior 71, 845-855.

Koch, S., Galloway, M.P., 1997. MDMA induced dopamine release in vivo: role of endogenous serotonin. Journal of Neural Transmission 104, 135-146.

Krystal, J.H., Price, L.H., Opsahl, C., Ricaurte, G.A., Heninger, G.R., 1992. Chronic 3,4-methylenedioxymethamphetamine (MDMA) use: effects on mood and neuropsychological function? American Journal of Drug and Alcohol Abuse 18, 331-341.

Lane, R.D., Fink, G.R., Chau, P.M., Dolan, R.J., 1997. Neural activation during selective attention to subjective emotional responses. Neuroreport 22, 3969-3972.

Ledoux, J.E., 1995. In searching of an emotional system in the brain: leaping from fear to emotion consciousness. In: Gazzanigan, M.S. (Ed.), The Cognitive Neuroscience. MIT Press, Cambridge, MA, pp. 1049-1061.

Liechti, M.E., Gamma, A., Vollenweider, F.X., 2001. Gender differences in the subjective effects of MDMA. Psychopharmacology 154, 161-168.

Lyketsos, C.G., Garrett, E., Liang, K.-Y., Anthony, J.C., 1999. Cannabis use and cognitive decline in persons under 65 years of age. American Journal of Epidemiology 149, 794-800.

Lyles, J., Cadet, J.L., 2003. Methylenedioxymethamphetamine (MDMA, Ecstasy) neurotoxicity: cellular and molecular mechanisms. Brain Research Reviews 42, 155-168.

McCann, U.D., Ricaurte, G.A., 1991. Lasting neuropsychiatric sequelae of ( \pm )-methylenedioxymethamphetamine ('ecstasy') in recreational users. Journal of Clinical Psychopharmacology 11, 302-305.

McCann, U.D., Ricaurte, G.A., 1992. MDMA ("ecstasy”) and panic disorder: induction by a single dose. Biology and Psychiatry 32, 950-953. 
McCann, U.D., Ricaurte, G.A., 1993. Strategies for detecting subclinical monoamine depletions in humans. NIDA Research Monograph 136, 53-60.

McCann, U.D., Szabo, Z., Scheffel, U., Dannals, R.F., Ricaurte, G.A., 1998. Positron emission tomographic evidence of toxic effect of MDMA ("ecstasy") on brain serotonin neurons in human beings. Lancet 352, 1433-1437.

McCardle, K., Luebbers, S., Carter, J.D., Croft, R.J., Stough, C., 2004. Chronic MDMA (ecstasy) use, cognition and mood. Psychopharmacology 173, 434-439.

Montoya, A.G., Sorrentino, R., Lukas, S.E., Price, B.H., 2002. Long-term neuropsychiatric consequences of "ecstasy" (MDMA): a review. Harvard Review of Psychiatry 10, 212-220.

Morris, J.S., Frith, C.D., Perrett, D.I., Rowland, D., Young, A.W., Calder, A.J., Dolan, R.J., 1996. A differential neural response in the human amygdala to fearful and happy facial expressions. Nature 383, 812-815.

Morris, J.S., Ohman, A., Dolan, R.J., 1998. Conscious and unconscious emotional learning in the human amygdala. Nature 393, 467-470.

Neiman, J., Haapaniemi, H.M., Hillbom, M., 2000. Neurological complications of drug abuse: pathophysiological mechanisms. European Journal of Neurology 7, 595-606.

Obrocki, J., Buchert, R., Vaterlein, O., Thomasius, R., Beyer, W., Schiemann, T., 1999. Ecstasy-long-term effects on the human central nervous system revealed by positron emission tomography. British Journal of Psychiatry $175,186-188$.

Obrocki, J., Schmoldt, A., Buchert, R., Andresen, B., Petersen, K., Thomasius, R., 2002. Specific neurotoxicity of chronic use of ecstasy. Toxicological Letters 127, 285-297.

Parrott, A.C., 2002. Recreational ecstasy/MDMA, the serotonin syndrome, and serotonergic neurotoxicity. Pharmacology Biochemistry and Behavior 71, 837-844.

Pope Jr., H.G., Gruber, A.J., Hudson, J.I., Huestis, M.A., Yurgelun-Todd, D., 2001. Neuropsychological performance in long-term cannabis users. Archives of General Psychiatry 58, 909-915.

Ranganath, C., Rainer, G., 2003. Neural mechanisms for detecting and remembering novel events. Natural Reviews in the Neuroscience 4, 193-202.

Reneman, L., Lavalaye, J., Schmand, B., de Wolff, F.A., van den Brink, W., den Heeten, G.J., Booij, J., 2001. Cortical serotonin transporter density and verbal memory in individuals who stopped using 3,4-methylenedioxymethamphetamine (MDMA or "ecstasy"): preliminary findings. Archives of General Psychiatry 58, 901-906.

Ricaurte, G.A., Yan, J., McCann, U.D., 2000. ( $\pm 3,4)$-Methylenedioxymethamphetamine (MDMA, “Esctasy”)induced serotonin neurotoxicity: studies in animals. Neuropsychobiology 42, 5-10.

Rogers, R.D., Robbins, T.W., 2001. Investigating the neurocognitive deficits associated with chronic drug misuse. Current Opinion in Neurobiology 11, 250-257.

Rossion, B., Campanella, S., Gomez, C.M., Delinte, A., Debatisse, D., Liard, L., Dubois, S., Bruyer, R., Crommelinck, M., Guerit, J.M., 1999. Task modulation of brain activity related to familiar and unfamiliar face processing: an ERP study. Clinical Neurophysiology 110, 449-462.

Rossion, B., Joyce, C.A., Cottrell, G.W., Tarr, M.J., 2003. Early lateralization and orientation tuning for face, word, and object processing in the visual cortex. Neuroimage 20, 1609-1624.

Rugg, M.D., Coles, M.G.H., 1995. Electrophysiology of mind. Event-related brain potentials and cognition. Oxford Psychology Series.

Semple, D.M., Ebmeier, K.P., Glabus, M.F., O'Carroll, R.E., Johnstone, E.C., 1999. Reduced in vivo binding to the serotonin transporter in the cerebral cortex of MDMA ('ecstasy') users. British Journal of Psychiatry 175, 6369.

Sohn, Y.H., Kim, G.W., Huh, K., Kim, J.S., 1998. Dopaminergic influences on the P300 abnormality in Parkinson's disease. Journal of Neurological Science 158, 83-87.

Solowij, N., Stephens, R.S., Roffman, R.A., Babor, T., Kadden, R., Miller, M., Christiansen, K., McRee, B., Vendetti, J., 2002. Cognitive functioning of long-term heavy cannabis users seeking treatment. Journal of the American Medical Association 287, 1123-1131.

Steele, T.D., McCann, U.D., Ricaurte, G.A., 1994. 3,4-Methylenedioxymethamphetamine (MDMA, “Esctasy”): pharmacology and toxicology in animals and humans. Addiction 89, 539-551.

Suwazano, S., Machado, L., Knight, R.T., 2000. Predictive value of novel stimuli modifies visual event-related potentials and behavior. Clinical Neurophysiology 111, 29-39. 
Thomasius, R., Petersen, K., Buchert, R., Andresen, B., Zapletalova, P., Wartberg, L., Nebeling, B., Schmoldt, A., 2003. Mood, cognition and serotonin transporter availability in current and former ecstasy (MDMA) users. Psychopharmacology 167, 85-96.

Verkes, R.J., Gijsman, H.J., Pieters, M.S., Schoemaker, R.C., de Visser, S., Kuijpers, M., Pennings, E.J., de Bruin, D., Van de Wijngaart, G., Van Gerven, J.M., Cohen, A.F., 2001. Cognitive performance and serotonergic function in users of ecstasy. Psychopharmacology (Berlin) 153, 196-202.

Volkow, N.D., Chang, L., Wang, G.J., Fowler, J.S., Leonido-Yee, M., Franceschi, D., Sedler, M.J., Gatley, S.J., Hitzemann, R., Ding, Y.S., Logan, J., Wong, C., Miller, E.N., 2001. Association of dopamine transporter reduction with psychomotor impairment in methamphetamine abusers. American Journal of Psychiatry 158, 377-382.

Whalen, P.J., Rauch, S.L., Etcoff, N.L., McInerney, S.C., Lee, M.B., Jenike, M.A., 1998. Masked presentations of emotional facial expressions modulate amygdale activity without explicit knowledge. Journal of Neuroscience $18,411-418$.

\section{Further reading}

Bouhuys, A.L., 2003. Ethology in depression. In: Philippot, P., Coats, E.J., Feldman, R.S. (Eds.), Nonverbal Behavior in Clinical Settings. Oxford University Press, New York.

Kornreich, C., Foisy, M.L., Philippot, P., Dan, B., Tecco, J., Noel, X., Hess, U., Pelc, I., Verbanck, P., 2003. Impaired emotional facial expression recognition in alcoholics, opiate dependence subjects, methadone maintained subjects and mixed alcohol-opiate antecedents subjects compared with normal controls. Psychiatry Research 119, 251-260.

Perez, J.E., Riggio, R.E., 2003. Nonverbal social skills and psychopathology. In: Philippot, P., Coats, E.J., Feldman, R.S. (Eds.), Nonverbal Behavior in Clinical Settings. Oxford University Press, New York.

Philippot, P., Bayens, C., Doulliez, C., Francart, B., 2003. Cognitive regulation of emotion: application to clinical disorders. In: Philippot, P., Feldman, R.S. (Eds.), The Regulation of Emotion. Laurence Erlbaum Associates, New York. 